\title{
Iron-regulated salicylate synthesis by Pseudomonas spp.
}

\author{
Paolo Visca, * Alessandra Ciervo, Vincenzo Sanfilippo and Nicola Orsi \\ Istituto di Microbiologia. Università di Roma 'La Sapienza', Piazzale Aldo Moro 5, 00185 Roma, Italy
}

(Received 23 December 1992; revised 3 April 1993; accepted 22 April 1993)

\begin{abstract}
Two iron-regulated compounds have been found in acidified ethyl acetate extracts from culture supernatants of Pseudomonas aeruginosa and Pseudomonas cepacia type-strains. Synthesis of both compounds paralleled irondeficient growth, and was repressed in the presence of $100 \mu \mathrm{M}-\mathrm{FeCl}_{3}$. Yields of these substances varied among different strains and attained maximum levels during stationary phase. Thin layer chromatographic analysis in five different solvent systems revealed that the slower-moving compound chromatographed as two distinct bands, and showed $\boldsymbol{R}_{F}$ values and spectral properties similar to pyochelin. The faster-moving compound co-migrated as a single band with a standard of commercial salicylic acid in each of the chromatographic systems tested. Moreover, a molecule with an identical $R_{F}$ was also produced by Pseudomonas fuorescens CHA401, which is known to synthesize salicylic acid as the only siderophore during iron-limited growth. Spectrophotometric and spectrofluorometric titrations led to the identification of this iron-regulated compound as salicylic acid, in agreement with the structure deduced from ${ }^{1} \mathrm{H}-\mathrm{NMR}$ and mass spectroscopy. The identity of the $P$. cepacia siderophore azurechelin as salicylic acid was also conclusively demonstrated. Salicylic acid, like pyochelin and pyoverdin, promoted $P$. aeruginosa growth in an iron-depleted medium. These results are consistent with a putative siderophore activity for salicylic acid, i.e. azurechelin, as has been demonstrated for $P$. aeruginosa, $P$. fluorescens and $\boldsymbol{P}$. cepacia. Thus, salicylic acid is likely to act as a siderophore in more than one species belonging to the genus Pseudomonas.
\end{abstract}

\section{Introduction}

In spite of its natural abundance, iron [ $\mathrm{Fe}(\mathrm{III})]$ is poorly available for most living organisms (Cox, 1989). To counter $\mathrm{Fe}(\mathrm{III})$ deficiency almost all bacteria and fungi have evolved high-affinity $\mathrm{Fe}$ (III) transport systems based on the synthesis of low-molecular-mass chelators (siderophores) and of their cognate receptors (Neilands, 1981, 1982). Siderophore-mediated Fe(III) acquisition is essential not only for the survival of micro-organisms in the environment, but also for the ability of bacterial and fungal parasites to establish and maintain infections (Cox, 1989; Weinberg, 1978).

Although the genus Pseudomonas includes several taxonomically and ecologically distinct bacteria, some species belonging to the first and second homology groups (Palleroni, 1984), i.e. $P$. aeruginosa and $P$. cepacia, synthesize a common siderophore, termed pyochelin, consisting of a salicyl-substituted cysteinyl peptide (Cox \& Graham, 1979; Cox et al., 1981; Sokol,

\footnotetext{
*Author for correspondence. Tel. 64991 4619; fax 649914626.
}

Abbreviation: HREI, high resolution electron impact.
1986). Apart from pyochelin, fluorescent pseudomonads synthesize additional siderophores generally termed pyoverdins (or pseudobactins in plant-related isolates) (Abdallah, 1991), whereas $P$. cepacia strains may also produce cepabactin (Meyer et al., 1989) and azurechelin (Sokol et al., 1992). Pyochelin has a relatively low affinity for $\mathrm{Fe}$ (III) $\left(K_{f}=2 \times 10^{5}\right)$ which is bound in a $2: 1$ stoichiometric ratio (Cox \& Graham, 1979; Visca et al., $1992 b$ ). Ferripyochelin uptake occurs via two distinct outer-membrane receptor proteins (Heinrichs et al., 1991; Sokol \& Woods, 1983). Pyochelin has been shown to form functionally active complexes with a variety of transition metals (Visca et al., 1992b), and has been associated with the virulence of $P$. aeruginosa in experimental mouse infections (Cox, 1982) and of $P$. cepacia in respiratory tract infections (Sokol \& Woods, 1988). Furthermore, a siderophore-like activity for salicylic acid, the biosynthetic precursor of pyochelin (Ankenbauer, \& Cox, 1988), has recently been recognized in P. fluorescens (Meyer et al., 1992).

In this paper we show that salicylic acid is not only an intermediate in pyochelin synthesis, but represents an authentic, endogenous siderophore for some $P$. aeruginosa, $P$. fluorescens and $P$. cepacia isolates. We also 
demonstrate that azurechelin, a siderophore of formerly unknown structure produced by $P$. cepacia (Sokol et al., 1992), is in fact salicylic acid.

\section{Methods}

Bacterial strains. P. aeruginosa PAOI (ATCC 15692), which produces pyoverdin (Abdallah, 1991) and pyochelin (Cox \& Graham, 1979), was obtained from the American Type Culture Collection. $P$. aeruginosa PA46U was isolated in the Institute of Microbiology of the University of Rome 'La Sapienza' from the urine of an infected patient; this isolate has been shown to synthesize both pyochelin and pyoverdin (Visca et al., 1991, 1992a). P. fluorescens CHAO, a soil isolate producing both pyoverdin and salicylate (Stutz et al., 1986; Meyer et al., 1992), and the pyoverdin-defective mutant CHA401 (Keel et al., 1989) derived from this strain by $\operatorname{Tn} 5$ insertion mutagenesis were kindly provided by D. Haas, Mikrobiologisches Institut, ETH, Zürich, Switzerland. The $P$. cepacia strains $P \mathrm{c} 275 \mathrm{c}$ and $\mathrm{Pc} 710 \mathrm{~m}$, producing both pyochelin and azurechelin, and $\mathrm{K} 30-6$ and $\mathrm{H} 1724-1$, producing azurechelin only, were a gift of P. Sokol, Department of Microbiology and Infectious Diseases, University of Calgary Health Sciences Centre, Alberta, Canada (Sokol et al., 1992).

Media and culture conditions. All pseudomonads, except $P$. fthorescens, were routinely grown in DCAA, containing $0.5 \%(\mathrm{w} / \mathrm{v})$ Casamino acids (Difco) in deionized, double distilled water, made metal-free by treatment with Chelex 100 resin (Bio-Rad). The activated resin was added to the Casamino acids solution $(5 \mathrm{~g}$ resin per litre medium) and the $\mathrm{pH}$ was adjusted to $7-2$ by the addition of a few drops of $1 \mathrm{M}-\mathrm{NaOH}$. After $16 \mathrm{~h}$ moderate stirring at $4{ }^{\circ} \mathrm{C}$ the resin was removed by filtration through Whatman no. 1 filter paper and the medium was sterilized by autoclaving. The medium was supplemented aseptically with $0.4 \mathrm{mM}-\mathrm{MgCl}_{2}$ immediately prior to inoculation. After Chelex 100 treatment, the Fe(III) content of DCAA, determined by means of an atomic absorption spectrophotometer (Perkin-Elmer model 360), was $<0.1 \mu \mathrm{M}$. Alternatively, M9 minimal medium (Guterman, 1973) was used after supplementation with 20 mM-sodium succinate as carbon source (SM9). The M9 basal solution was also treated with $5 \mathrm{~g}$ Chelex $100 \mathrm{l}^{-1}$ as described above. When required,

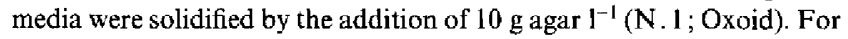
$P$. fluorescens isolates, which grew poorly in DCAA, the $\mathrm{Fe}$ (III)deprived $\mathrm{M} 9$ medium supplemented with $20 \mathrm{mM}$-sodium succinate and $5 \mathrm{~g}$ Casamino acids $1^{-1}$ (SM9CAA) was used.

To deplete the cells of intracellular Fe(III) pools, bacteria were first cultured on SM9 agar plates, suspended in a small volume of sterile, double distilled water to an $\mathrm{OD}_{620}$ of 0.5 and inoculated in DCAA or SM9CAA (approximately $10^{6}$ cells $\mathrm{ml}^{-1}$ ). The culture was incubated at $37^{\circ} \mathrm{C}$ in a rotary shaker at $250 \mathrm{rev}$. $\mathrm{min}^{-1}$ until late exponential phase. This culture was subsequently used as inoculum to achieve a final concentration of approximately $10^{6}$ cells $\mathrm{ml}^{-1}$.

All glassware was rendered iron-free by $24 \mathrm{~h}$ treatment with $0.1 \mathrm{M}-$ $\mathrm{HCl}$, rinsed once in distilled water and finally rinsed in deionized, double distilled water before sterilization. All media and solutions were prepared with deionized, double distilled water. Commercial salicylic acid and its sodium salt were purchased from Aldrich.

Extraction and characterization of pyochelin and salicylic acid. Pyochelin and salicylic acid were isolated by ethyl acetate extraction of acidified supernatants obtained after centrifugation $(5000 \mathrm{~g}, 30 \mathrm{~min}$, $4^{\circ} \mathrm{C}$ ) of $36 \mathrm{~h}$ bacterial cultures in DCAA or SM9CAA. Briefly, the spent medium was adjusted to $\mathrm{pH} 1 \cdot 5-2 \cdot 0$ with $1 \cdot 0 \mathrm{M}-\mathrm{HCl}$ and extracted twice with 0.4 vols ethyl acetate. After evaporation of the organic phase under vacuum, the dry residue was resuspended in a small volume of methanol and applied in triplicate to a Silica gel $G$ thin layer chromatography (TLC) plate which was developed in solvent I (chloroform/acetic acid/ethanol, $90: 5: 2 \cdot 5$, by vol.).

Pyochelin from TLC plates was qualitatively characterized by: (i) yellow-green fluorescence emission under UV light (Cox \& Graham, 1979); (ii) iron binding capacity resulting in red-brown spots when sprayed with $0.1 \mathrm{M}-\mathrm{FeCl}_{3}$ in $0.1 \mathrm{M}-\mathrm{HCl}$ (Cox \& Graham, 1979); (iii) specific reactivity of $\mathrm{N}$-methylthiazolidine rings yielding black spots when sprayed with ammoniacal silver nitrate reagent (Kirchner, 1967; Ankenbauer \& Cox, 1988); (iv) chromatographic mobility $\left[R_{F}=\right.$ 0.35-0-40 in solvent I (Ankenbauer et al., 1991)]. Salicylic acid from TLC plates was qualitatively characterized by (i) blue fluorescence emission under UV light (Feigl, 1960); (ii) iron-binding capacity resulting in red-violet spots when sprayed with $0.1 \mathrm{M}-\mathrm{FeCl}_{3}$ in $0.1 \mathrm{M}-$ $\mathrm{HCl}$ (Meyer et al., 1992); (iii) chromatographic mobility in comparison with a standard of commercial salicylic acid $\left(R_{F}=0.60\right)$.

For TLC analysis five different solvent systems were used: solvent I, chloroform/acetic acid/ethanol (90:5:2.5, by vol.); solvent II, chloroform/acetic acid $(90: 1, \mathrm{v} / \mathrm{v})$; solvent III, chloroform/ethanol $(4: 1, \mathrm{v} / \mathrm{v})$; solvent IV, 2 -propanol $/ 25 \%(\mathrm{w} / \mathrm{v})$ ammonium hydroxide/ water $(100: 10: 10$, by vol.); solvent $\mathrm{V}$, benzene/toluene/acetic acid (2:2:1, by vol.). Solvents I-IV were from Cox \& Graham (1979) and Meyer et al. (1989), while solvent V was from Saxena et al. (1986).

Quantitative assays of pyochelin and salicylic acid were done by scraping the fluorescent spots from TLC plates loaded with extracts from $50 \mathrm{ml}$ cultures. The compounds were eluted from the silica gel by extracting twice with methanol. The methanol extracts were dried under vacuum and the amounts of pyochelin and salicylic acid determined by spectrophotometric titrations of the desferri- and ironsaturated forms in the $230-630 \mathrm{~nm}$ wavelength range, in comparison with known standards.

Large-scale preparations of pyochelin and salicylic acid were made by growing strains in stirred 1 litre flasks containing $250 \mathrm{ml}$ DCAA or SM9CAA; the supernatants obtained after centrifugation were acidified, extracted with ethyl acetate, and sequentially chromatographed in solvents I and V as described above. Preparative HPLC was performed according to minor modifications of the procedures of Meyer $e t$ al. (1992). When possible, salicylate and pyochelin were protected from light and stored in dark containers.

Chemical analysis. Absorption spectra in the visible and UV ranges $(230-630 \mathrm{~nm})$ were measured at $20^{\circ} \mathrm{C}$ with a Beckman model 25 spectrophotometer. Titrations were performed at $\mathrm{pH} 6$ by stepwise addition of $\mathrm{FeCl}_{3}$ from solutions prepared in equimolar concentrations of $\mathrm{HCl}$. Under the solvent condition chosen, the solubility of pyochelin, salicylate and their complexes with Fe(III) is high and the absorption spectra of desferri-forms and complexes with $\mathrm{Fe}$ (III) have been reported (Cox \& Graham, 1979; Meyer et al., 1992; Ungar et al., 1952; Visca et al., 1992b).

Fluorescence excitation and emission spectra were performed in $97 \%$ (v/v) methanol, $30 \mathrm{~mm}$-Tris (pH 11) using a Jasco FP-770 spectrofluorometer.

High resolution electron impact (HREI) mass spectra were obtained on an Apex 47e Spectrospin Bruker ion cyclotrone resonance spectrometer.

${ }^{1} \mathrm{H}$-NMR analyses of compounds dissolved in $\mathrm{CD}_{3} \mathrm{OD}$ were performed in a Bruker 500 spectrometer using TMS as internal standard. The identification of salicylic acid was made by direct comparison with the commercial standard.

Measurement of bacterial growth rates. $P$, aeruginosa strains from SM9 agar plates were inoculated into $25 \mathrm{ml}$ DCAA and grown overnight at $37^{\circ} \mathrm{C}$ with vigorous shaking to deplete cells of essential metals. Bacterial cells were centrifuged $\left(20 \mathrm{~min}, 2500 \mathrm{~g}, 37^{\circ} \mathrm{C}\right.$ in a Heraeus Omnifuge 2.0 RS centrifuge), resuspended in pre-warmed $\mathrm{DCAA}$ to an $\mathrm{OD}_{620}$ of $1 \cdot 0$, and $0.1 \mathrm{ml}$ aliquots of bacterial suspension were used to inoculate $25 \mathrm{ml}$ pre-warmed DCAA in $350 \mathrm{ml}$ Erlenmeyer 
(a)

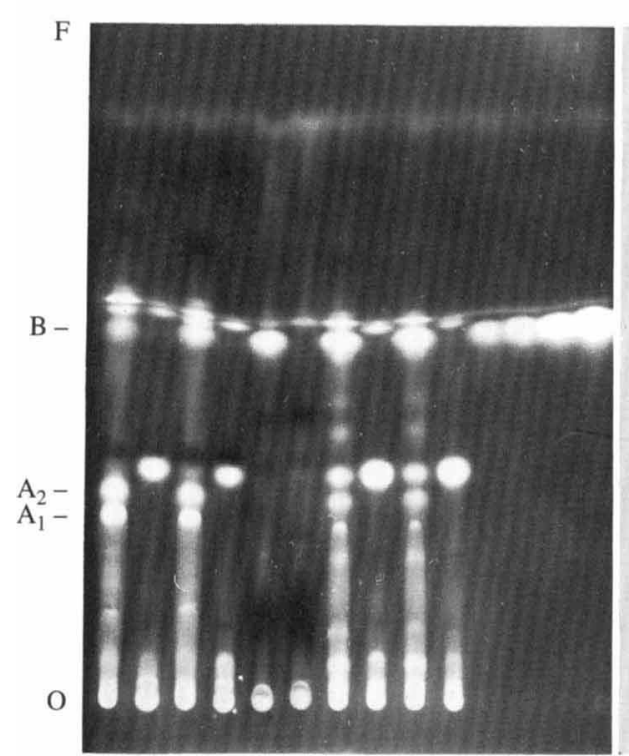

(b)

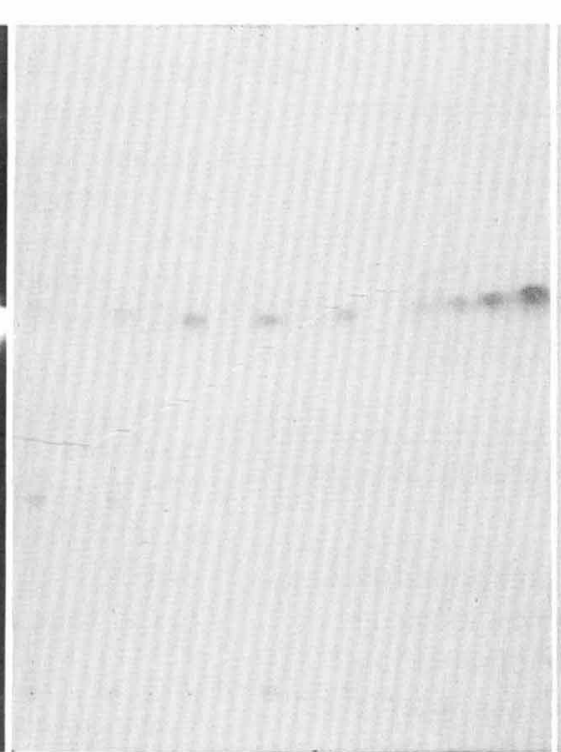

(c)

$\begin{array}{llllllllllllllllllllllllllllllllllllllllllllllll}1 & 2 & 3 & 4 & 5 & 6 & 7 & 8 & 9 & 10 & 11 & 12 & 13 & 14 & 1 & 2 & 3 & 4 & 5 & 6 & 7 & 8 & 9 & 10 & 11 & 12 & 13 & 14 & 1 & 2 & 3 & 4 & 5 & 6 & 7 & 8 & 9 & 10 & 11 & 12 & 13 & 14\end{array}$

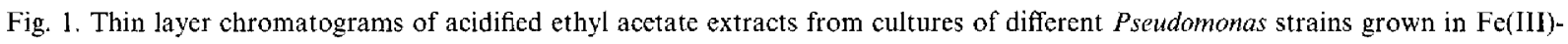
deficient and $\mathrm{Fe}(\mathrm{III})$-rich medium. In the $\mathrm{Fe}(\mathrm{III})$ rich conditions $\mathrm{FeCl}_{3}$ was added to DCAA or SM9CAA at a final concentration of $100 \mu \mathrm{M}$ (see Methods). Lanes: 1 and 2, $P$. aeruginosa $\mathrm{PAO}$ in $\mathrm{Fe}(\mathrm{III})$-poor and $\mathrm{Fe}(\mathrm{III})$-rich medium, respectively; 3 and 4, $P$. aeruginosa PA46U in Fe(III)-poor and Fe(III)-rich medium, respectively; 5 and 6, $P$. fluorescens $\mathrm{CHA} 40 \mathrm{I}$ in $\mathrm{Fe}$ (III)-poor and Fe(III)-rich medium, respectively; 7 and 8, P. cepacia $\mathrm{Pc} 275 \mathrm{c}$ in $\mathrm{Fe}(\mathrm{III})$-poor and Fe(III)-rich medium, respectively; 9 and 10 , $P$. cepacia $\mathrm{HI}$ 724-1 in $\mathrm{Fe}(\mathrm{III})-$ poor and $\mathrm{Fe}(\mathrm{III})$-rich medium, respectively; 11-14, 5, 10, 20 and $40 \mathrm{nmol}$ commercial salicylic acid, respectively. (a) Chromatograms visualized by exposure to UV light; (b) chromatograms developed by spraying with $0 \cdot 1 \mathrm{M}-\mathrm{FeCl}_{3}$ in $0 \cdot 1 \mathrm{M}-\mathrm{HCl} ;(c)$ chromatograms developed by spraying with the ammoniacal silver nitrate reagent for thiazolidine groups (Kirchner, 1967). Abbreviations: $F$, solvent front; $\mathrm{O}$, origin of migration; $\mathrm{A}_{1}, \mathrm{~A}_{2}$ and $\mathrm{B}$, compounds $\mathrm{A}_{1}, \mathrm{~A}_{2}$ and $\mathrm{B}$. Lanes 1 to 10 were loaded with the equivalent of $3.5 \mathrm{ml}$ culture extracts.

flasks. Cultures were incubated at $37^{\circ} \mathrm{C}$ with aeration in an orbital shaker (New Brunswick, model G25) at $250 \mathrm{rev} \cdot \mathrm{min}^{-1}$ and $1 \mathrm{ml}$ aliquots were removed at hourly intervals for measurement of $O D_{620}$. The rate of biomass increase was estimated over $6 \mathrm{~h}$ after inoculation and the mean generation time was determined as previously described (Visca et al., 1992b).

\section{Results and Discussion}

$\mathrm{Fe}(\mathrm{III})$-regulated compounds in ethyl acetate extracts of supernatants from Pseudomonas spp.

TLC analysis in solvent I of supernatants from cultures of different Pseudomonas strains grown in Fe(III)depleted and $\mathrm{Fe}$ (III)-rich media is shown in Fig. 1. Three different $\mathrm{Fe}(\mathrm{III})$-regulated compounds were observed, provisionally termed $\mathrm{A}_{1}, \mathrm{~A}_{2}$ and $\mathrm{B}$, with $R_{F}$ values of $0.35,0.39$ and 0.60 , respectively. Compounds $A_{1}$ and $A_{2}$ exhibited green-grey fluorescence under UV light, turned brown-red on reaction with $\mathrm{Fe}(\mathrm{III})$, and gave a positive reaction for thiazolidine rings which are known to form black silver mercaptide salts during alkaline hydrolysis in the presence of $\mathrm{Ag}(\mathrm{I})$ (Kirchner, 1967; Ankenbauer et al., 1988). Compounds $A_{1}$ and $A_{2}$ were produced by all the strains examined, except $P$. fluorescens $\mathrm{CHAO}$ and its pyoverdin-defective derivative CHA401. However, the level of compounds $A_{1}$ and $A_{2}$ was significantly lower in $P$. cepacia than in $P$. aeruginosa strains. Compound $\mathrm{B}$ exhibited an evident blue-violet fluorescence under UV light and reacted with $\mathrm{Fe}(\mathrm{III})$ yielding red-violet spots, but did not turn black upon reaction with the ammoniacal silver nitrate reagent for thiazolidine groups. Compound $B$ was synthesized by each of the species tested. Remarkably, synthesis of compounds $\mathrm{A}_{1}, \mathrm{~A}_{2}$ and $B$ appeared to be repressed in cultures supplemented with $100 \mu \mathrm{M}-\mathrm{FeCl}_{3}$. Compounds $\mathrm{A}_{1}$ and $\mathrm{A}_{2}$ displayed the same chromatographic mobility and chemical reactivity as pyochelin from $P$. aeruginosa $\mathrm{PAO}$ which, under the solvent conditions chosen, is known to migrate as two distinct $\mathrm{Fe}(\mathrm{III})$ and $\mathrm{Ag}(\mathrm{I})$ reactive forms of $R_{R^{\prime}} 0 \cdot 30-0 \cdot 40$, probably corresponding to pyochelin I $\left(R_{F} 0.35\right)$ and pyochelin II $\left(R_{F} 0 \cdot 40\right)$ (Ankenbauer et al., 1988). Compound B exhibited chromatographic mobility, fluorescence emissions and chemical reactivity identical to that of commercial salicylic acid (Fig. 1) and resembled that described by Sokol et al. (1992) for azurechelin. Emission of blue-violet fluorescence under UV light is a typical spot test in the qualitative analysis of salicylates 
Table 1. TLC $R_{F}$ values of Fe(III)-regulated compounds in ethyl acetate extracts of culture supernatants from different Pseudomonas spp.

\begin{tabular}{lccccc}
\hline \hline & \multicolumn{5}{c}{$R_{F}$ value in solvent* } \\
\cline { 2 - 6 } Compound & I & II & III & IV & V \\
\hline B & 0.60 & 0.69 & 0.57 & 0.64 & 0.61 \\
A $_{1}$ & 0.39 & 0.33 & 0.37 & 0.55 & 0.32 \\
A $_{2}$ & 0.35 & 0.25 & 0.35 & 0.32 & 0.21 \\
Salicylic & 0.60 & 0.69 & 0.56 & 0.64 & 0.61 \\
acid & & & & & \\
\hline
\end{tabular}

* See Methods for the composition of solvents and TLC plates used.

(Feigl, 1960). The hypothesis that compound B and azurechelin might correspond to the same molecule, i.e. salicylic acid, was strengthened by the observation that compound B was the only $\mathrm{Fe}$ (III)-regulated substance in culture extracts of $P$. fluorescens CHA401, which is known to synthesize salicylic acid as the only siderophore during $\mathrm{Fe}(\mathrm{III})$-limited growth (Meyer et al., 1992). As in the case of azurechelin (Sokol et al., 1992), compound B gave a negative reaction in the Arnow (1937) assay for catechols and in the Gillan et al. (1981) assay for hydroxamates, as expected for salicylic acid.

Development of TLC plates in five different solvent systems consistently resolved the three $\mathrm{Fe}(\mathrm{III})$-regulated bands as detectable by fluorescence emission and reactivity with $\mathrm{Fe}(\mathrm{III})$ and/or $\mathrm{Ag}(\mathrm{I})$ ions (Table 1). Compounds $\mathrm{A}_{1}$ and $\mathrm{A}_{2}$ migrated in all solvents as two discrete bands, with $R_{F}$ values roughly corresponding to those reported for pyochelin (Cox \& Graham, 1979;
Meyer et al., 1989). The chromatograms also confirmed the virtual identity of compound B as salicylic acid, both migrating with the same $R_{F}$ in all solvent systems tested.

The synthesis of both compounds in Fe(III)-depleted media paralleled bacterial growth and attained the maximum during the stationary phase at which stage the level of compounds $A_{1}-A_{2}$ (pyochelin) and $B$ (salicylic acid) varied in a range $0-26 \mu \mathrm{M}$ and $27-59 \mu \mathrm{M}$, respectively, depending upon the strain (data not shown).

TLC analysis of culture extracts from 121 clinical isolates of $P$. aeruginosa revealed that only $13.2 \%$ produced detectable amounts of compound $B$, while $97.5 \%$ produced compounds $A_{1}$ and $A_{2}$. It is interesting to note that one out of the three $P$. aeruginosa isolates defective in the synthesis of compounds $A_{1}$ and $A_{2}$ was found to release very large amounts of compound $B$.

\section{Chemical characterization of $\mathrm{Fe}(I I I)$-regulated compounds in ethyl acetate extracts from Pseudomonas spp.}

The results presented above strongly support the hypothesis that compound $\mathbf{B}$ and azurechelin may correspond to salicylic acid and prompted us to perform spectrophotometric analyses of these molecules and their complexes with Fe(III). The UV-visible spectra (230$630 \mathrm{~nm}$ ) were obtained in a methanol solution at $\mathrm{pH} 6.0$ containing compound $\mathbf{B}$ adjusted to a concentration spectrophotometrically equivalent to $100 \mu \mathrm{M}$-salicylic acid (Fig. 2). Under these conditions compound B displayed an absorption spectrum identical to salicylic acid with maxima at $298 \mathrm{~nm}\left(\varepsilon=5220 \mathrm{M}^{-1} \mathrm{~cm}^{-1}\right)$ and
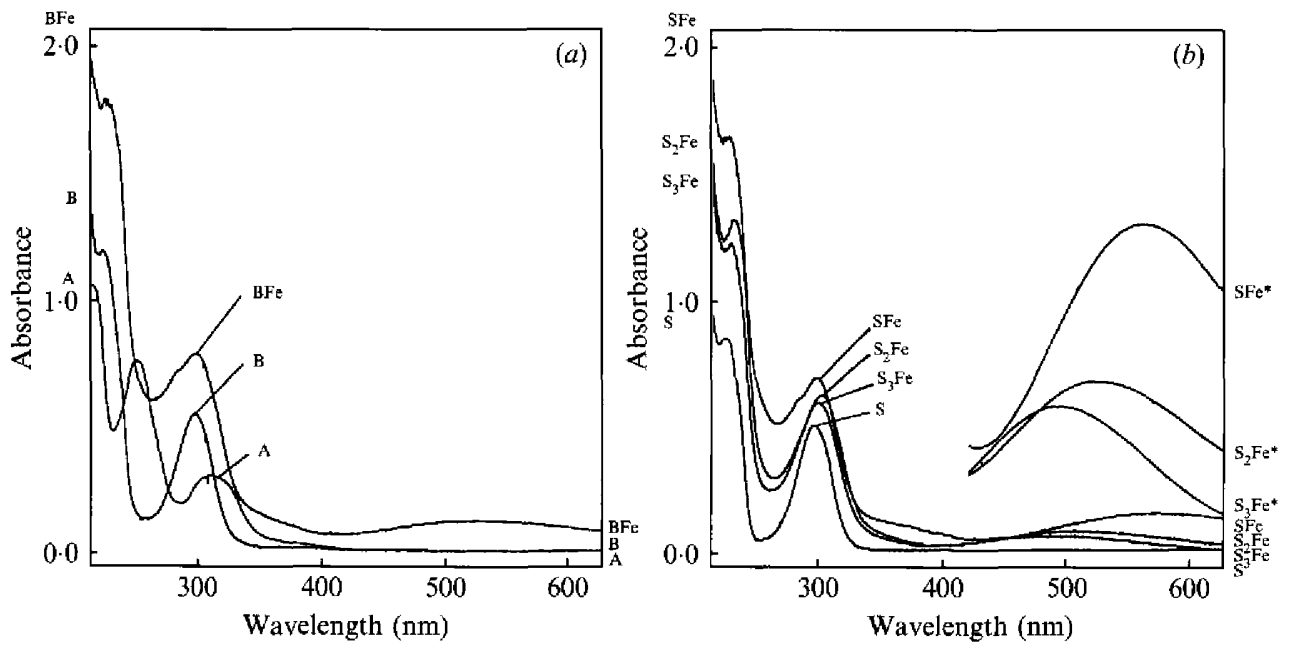

Fig. 2. (a) Absorption spectra of methanolic solutions at pH 6 of (A) compound A from P. aeruginosa PA46U, (B) compound B from $P$. cepacia $\mathrm{PC} 275 \mathrm{c}$, and $(\mathrm{BFe})$ compound $\mathrm{B}$ saturated with a theoretically equimolar amount of $\mathrm{FeCl}_{3}$. The concentration of compound B was spectrophotometrically adjusted to a value approximately equivalent to $100 \mu \mathrm{M}$-salicylic acid. (b) Titration of a methanolic solution of commercial salicylic acid with $\mathrm{FeCl}_{3}$. S, $100 \mu \mathrm{M}$-salicylic acid; $\mathrm{S}_{3} \mathrm{Fe}, \mathrm{S}_{2} \mathrm{Fe}$ and $\mathrm{SFe}, 100 \mu \mathrm{M}-\mathrm{salicylate}-\mathrm{Fe}$ (III) complexes in 3:1,2:1 and $1: 1$ stoichiometric ratios, respectively; $\mathrm{S}_{3} \mathrm{Fe}^{*}, \mathrm{~S}_{2} \mathrm{Fe}^{*}$ and $\mathrm{SFe} e^{*}, 800 \mu \mathrm{M}$-salicylate-Fe(III) complexes in $3: 1$, $2: 1$ and $1: 1$ stoichiometric ratios, respectively. 


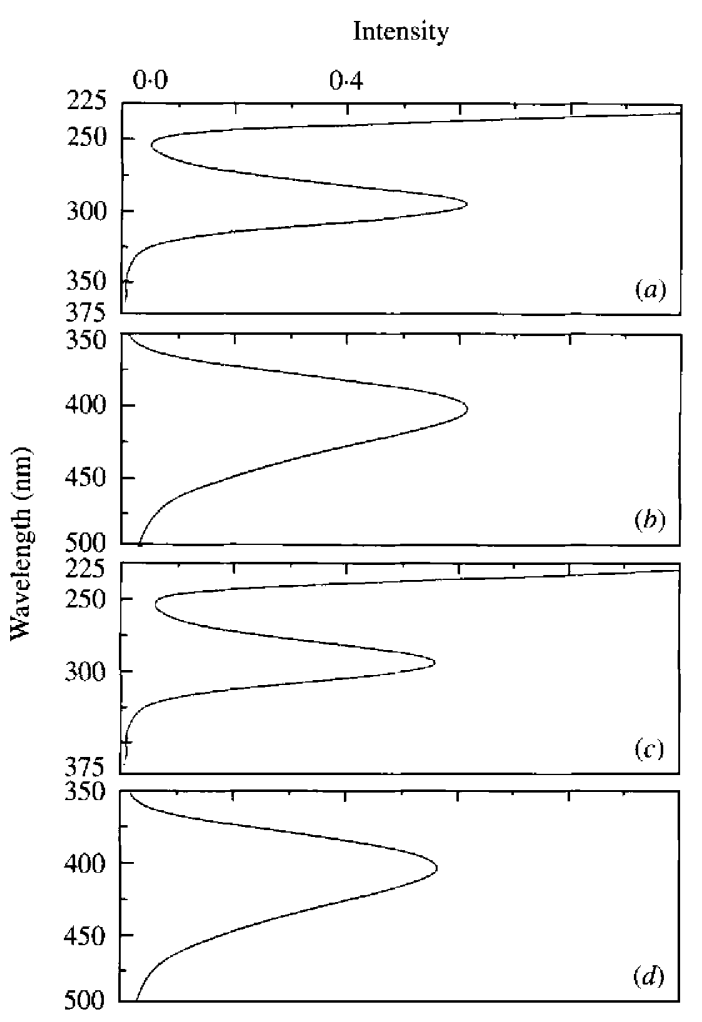

Fig. 3. Fluorescence spectra of $1.66 \mu \mathrm{M}$ commercial salicylic acid $(a, b)$ and compound $\mathrm{B}$ from $P$. cepacia $\mathrm{Pc} 275 \mathrm{c}(c, d)$ dissolved in $97 \%$ methanol, $30 \mathrm{~mm}$-Tris, pH 11. (a, c) Excitation spectra with emission measured at $405 \mathrm{~nm} ;(b, d)$ emission spectra upon excitation at $295 \mathrm{~nm}$.

$240 \mathrm{~nm}\left(\varepsilon=8440 \mathrm{M}^{-1} \mathrm{~cm}^{-1}\right)$ as shown by spectra $\mathrm{B}$ and $\mathrm{S}$ in Fig. 2. Saturation of compound B and salicylic acid with an equimolar amount of $\mathrm{Fe}$ (III) caused an evident spectral transition for both compounds with the presence of an additional absorption maximum in the visible region at approximately $550 \mathrm{~nm}$. To analyse the formation of complexes between salicylic acid and $\mathrm{Fe}(\mathrm{III})$ titration experiments were performed (spectra $\mathrm{S}_{3} \mathrm{Fe}^{*}$, $\mathrm{S}_{2} \mathrm{Fe}^{*}$ and $\mathrm{SFe}^{*}$ in Fig. $2 b$ ). The spectral changes observed at increasing salicylate/Fe(III) molar ratios suggest the formation of complexes with different stoichiometry, namely $1: 1,2: 1$ and $3: 1$, characterized by absorption maxima in the visible region at $555 \mathrm{~nm}(\varepsilon=$ $\left.1600 \mathrm{M}^{-1} \mathrm{~cm}^{-1}\right), 516 \mathrm{~nm}\left(\varepsilon=837 \mathrm{M}^{-1} \mathrm{~cm}^{-1}\right)$ and $490 \mathrm{~nm}$ $\left(\varepsilon=710 \mathrm{M}^{-1} \mathrm{~cm}^{-1}\right)$, respectively. It should also be pointed out that salicylate is known to provide a very efficient $\mathrm{Fe}$ (III)-binding centre and generate salicylate-Fe(III) complexes characterized by high stability constants, their $\log K_{f} \quad\left(1 \mathrm{M}, \quad 25^{\circ} \mathrm{C}\right)$ ranging from 15.8 for the monosalicylate-Fe(III) complex to $35 \cdot 3$ for the trisalicylate-Fe(III) complex (Martell \& Smith, 1977).

The UV-visible absorption spectra of compounds $A_{1}$ and $A_{2}$ were determined under the same solvent conditions described above. The results obtained (spectrum A in Fig. $2 a$ ) indicate that compounds $\mathrm{A}_{1}$ and
$\mathrm{A}_{2}$ correspond to pyochelin, since each showed typical absorption maxima at 250 and $310 \mathrm{~nm}$, as previously reported by Cox \& Graham (1979). Moreover, compounds $A_{1}$ and $A_{2}$ did not exhibit any difference in their spectroscopic properties in the UV-visible range (data not shown), as reported by Ankenbauer et al. (1988) for the two forms of pyochelin.

Our assumption that compound $\mathbf{B}$ and azurechelin are both salicylic acid was further strengthened by fluorimetric analyses (Fig. 3). The analyses were carried out by dissolving both compounds in $97 \%(\mathrm{v} / \mathrm{v})$ methanol, 30 mM-Tris ( $\mathrm{pH} 11 \cdot 0)$, to achieve a final concentration of $1.66 \mu \mathrm{M}$. The results obtained show that compound B (from $P$. cepacia $P$ c275c) displayed excitation and emission spectra identical to those observed for salicylic acid, with excitation and emission maxima at 295 and $404 \mathrm{~nm}$, respectively.

The UV-visible and fluorescence spectra of compounds $A_{1}, A_{2}$ and $B$ were compared for all the strains examined. Each compound appeared to be homogeneous as no difference was observed among compounds $\mathrm{A}_{1}, \mathrm{~A}_{2}$ and $\mathrm{B}$ extracted from the different Pseudomonas strains. The possibility that compound B (salicylic acid) could originate from spontaneous degradation of compounds $A_{1}$ and $A_{2}$ (pyochelin) was ruled out by our observations that prolonged incubation of the last two substances in acid ( $\mathrm{pH} \mathrm{1.5)} \mathrm{or} \mathrm{alkali}(\mathrm{pH}$ 12.8) did not generate compound $\mathrm{B}$, as detectable after acidified ethyl acetate extraction and TLC analysis.

That compound B and azurechelin are both salicylic acid was conclusively confirmed by means of ' $\mathrm{H}-\mathrm{NMR}$ and HREI mass spectroscopy. The HREI spectroscopic analysis of freshly purified compound $B$ resembled that of commercial salicylic acid, both compounds showing the same fragmentation pattern with main ions at $\mathrm{m} / \mathrm{z}$ values of 138, 94 and 66 . The 'H-NMR spectral characteristics of compound $\mathrm{B}$ dissolved in $\mathrm{CD}_{3} \mathrm{OD}$ are given in Fig. 4, together with the deduced formula. The HREI and NMR data together with those deduced from TLC analysis and UV-visible and fluorescence spectroscopy, led us to the unequivocal conclusion that compound B and azurechelin are salicylic acid.

\section{Growth promoting activity of salicylic acid and its complexes with $\mathrm{Fe}(I I I)$}

The ability of salicylic acid to function as a siderophore has already been shown in P. fluorescens (Meyer et al., 1992) and P. cepacia (Sokol et al., 1992). To investigate the involvement of salicylic acid in Fe(III) transport by $P$. aeruginosa, we compared the growth rates of strains PAO1 and PA46U in Fe(III)-depleted medium (DCAA) supplemented with salicylate and the salicylate/Fe(III) $3: 1$ complex. The results obtained (Table 2) indicate that 
(a)

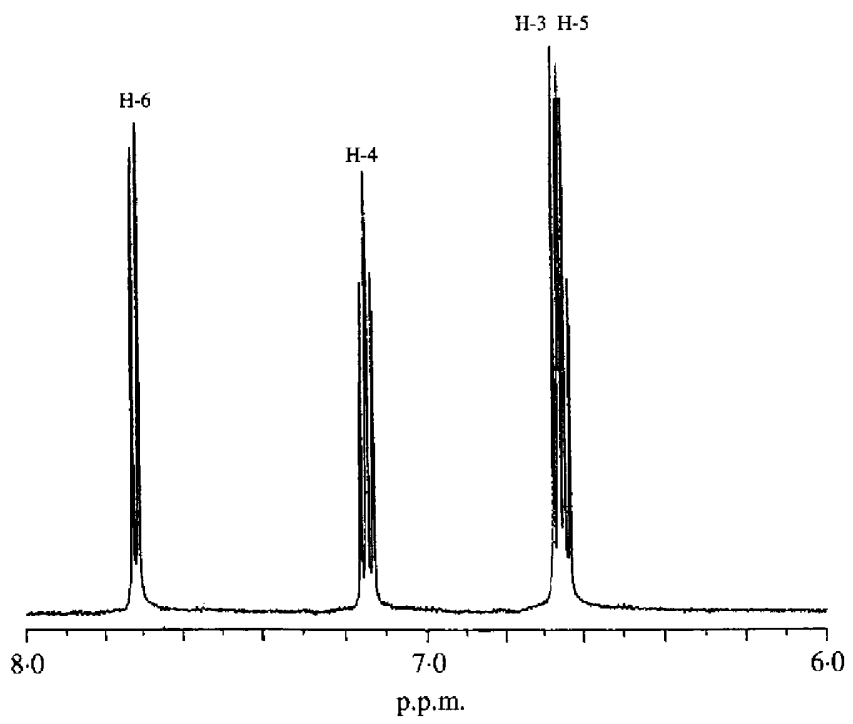

(b)

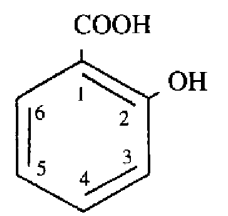

Fig. 4. 'H-NMR spectrum ( $a$ ) and deduced formula (b) of compound B.

Table 2. Effect of salicylate and its $\mathrm{Fe}(I I I)$-complex on Pseudomonas aeruginosa growth in metal-poor medium $(D C A A)$

Values are means $( \pm S D)$ of triplicate experiments performed with a single DCAA preparation. Fe(III) was added as $10 \mu \mathrm{M}-\mathrm{FeCl}_{3}$; salicylate was added either as sodium salt or as Fe(III)-complex [3:1, salicylate/Fe(III) molar ratio] at $30 \mu \mathrm{M}$.

\begin{tabular}{lcccc}
\hline \hline & \multicolumn{4}{c}{$\begin{array}{c}\text { Mean generation time (min) in DCAA } \\
\text { supplemented with: }\end{array}$} \\
\cline { 2 - 5 } Strain & Nil & Fe(III) & Salicylate & $\begin{array}{c}\text { Fe(III)- } \\
\text { salicylate }\end{array}$ \\
\hline PAO1 & $75 \cdot 2( \pm 3 \cdot 6)$ & $48 \cdot 1( \pm 0 \cdot 9)$ & $68 \cdot 4( \pm 2 \cdot 4)$ & $42 \cdot 3( \pm 1 \cdot 7)$ \\
PA46U & $68 \cdot 7( \pm 4 \cdot 5)$ & $43 \cdot 6( \pm 2 \cdot 3)$ & $61 \cdot 0( \pm 3 \cdot 9)$ & $39 \cdot 8( \pm 1 \cdot 1)$ \\
\hline \hline
\end{tabular}

growth of both $P$. aeruginosa strains under conditions of limiting $\mathrm{Fe}(\mathrm{III})$ is promoted by salicylate and, to a greater extent, by its complex with Fe(III). Since both strains were unable to use salicylate as their sole carbon source, such growth stimulation might be ascribed to salicylate-mediated Fe(III) acquisition. These functional effects of salicylate and its $\mathrm{Fe}$ (III)-complexes parallel those previously demonstrated for pyoverdin and pyochelin and their ferri-forms (Visca et al., 1992b).

The interesting parallels observed for the synthesis and the functional effects of salicylate in Pseudomonas spp. and other bacterial genera is worth noting. Salicylic acid is a precursor of pyochelin in $P$. aeruginosa (Ankenbauer \& Cox, 1988) and mycobactin in Mycobacterium spp. (for a review see Ratledge, 1987) and is synthesized by pseudomonads and mycobacteria in response to Fe(III)limited growth (Meyer et al., 1992; Ratledge \& Winder, 1962). Moreover, salicylate is endowed with a siderophore-like activity in Mycobacterium spp. (Ratledge, 1987; Ratledge \& Winder, 1962; Ratledge et al., 1974), Azospirillum lipoferum (Saxena et al., 1986), $P$. aeruginosa (Meyer, 1992) and $P$. fuorescens (Meyer et al., 1992), although its $\mathrm{Fe}(\mathrm{III})$-sequestering properties in the presence of competing or precipitating ligands are questionable (Ratledge et al., 1974). The mechanism of translocation of the $\mathrm{Fe}$ (III)-salicylate complex(es) into the cell is unclear. It is tempting to speculate that they enter the cell via specific receptors. Due to the structural similarities of salicylate with pyochelin, obvious candidates for $\mathrm{Fe}$ (III)-salicylate transport, at least in $P$. aeruginosa PAOl, are the $14 \mathrm{kDa}$ and $75 \mathrm{kDa}$ ferripyochelin uptake proteins (Heinrichs et al., 1991; Sokol \& Woods, 1983). However, similarly to pyochelin, salicylate and its complexes with Fe(III) are poorly water-soluble (Ratledge et al., 1974) and might therefore associate with the lipid layer of the bacterial outer membrane. It will be of interest to determine whether salicylate may induce the expression of specific ironregulated outer-membrane protein(s) involved in ferrisiderophore uptake, as already shown for pyochelin and pyoverdin in P. aeruginosa (Gensberg et al., 1992).

Taken together, the results presented here demonstrate that $P$. aeruginosa and $P$. cepacia, as well as $P$. fluorescens, synthesize salicylate during Fe(III)-limited growth. Indeed, UV-visible spectroscopic properties determined for compound $\mathrm{B}$ are in line with those previously published for salicylic acid (Boltz \& Schenk, 1963; Ungar et al., 1952), as are data derived from fluorescence, HREI and NMR analysis (Weissler \& White, 1963; Marshall \& Ratledge, 1972). We have also demonstrated that azurechelin, formerly identified in $P$. cepacia by Sokol et al. (1992) is in fact salicylic acid. In all the strains examined production of salicylate occurred in response to $\mathrm{Fe}$ (III)-starvation, thus leading to the hypothesis that it is involved in Fe(III)-uptake. This contention was supported by the significant growthpromoting activity of salicylate and its $\mathrm{Fe}$ (III)-complex under conditions of $\mathrm{Fe}$ (III)-deficiency.

\footnotetext{
We are grateful to Professor V. Galeffi (Istituto Superiore di Sanità, Roma) and to Professor F. Cacace (Dipartimento di Studi di Chimica e Tecnologia delle Sostanze Biologicamente Attive) for helpful discussions. This work was supported by a MURST grant from the project 'Control of Microbial Pathogenicity', and by a CNR grant from the targeted project 'Prevention and Control of Disease Factors'.
} 


\section{References}

ABdallah, M. A. (1991). Pyoverdins and pseudobactins. In $C R C$ Handbook of Microbial Iron Chelates, pp. 139-153. Edited by G. Winkelmann. Boca Raton: CRC Press.

AnKendauer, R. G. \& Cox, C. D. (1988). Isolation and characterization of Pseudomonas aeruginosa mutants requiring salicylic acid for pyochelin biosynthesis. Journal of Bacteriology 170, 5364-5367.

Ankenbauer, R. G., Staley, A. L., Rinehart, K. L. \& Cox, C. D. (1991). Mutasynthesis of siderophore analogues by Pseudomonas aeruginosa. Proceedings of the National Academy of Sciences of the United States of America 88, 1878-1882.

ankenbauter, R. G., Toyokuni, T., Staley, A., Rinehart, K. L. \& Cox, C. D. (1988). Synthesis and biological activity of pyochelin, a siderophore of Pseudomonas aeruginosa. Journal of Bacteriology 170, 5344-5351.

ARNow, L. E. (1937). Colorimetric determination of the components of 3,4-dihydroxyphenylalanine-tyrosine mixtures. Journal of Biological Chemistry 118, 531-537.

BOLTZ, D. F. \& SCHENK, G. H. (1963). Visible and ultraviolet spectroscopy. In Handbook of Analytical Chemistry, pp. 6/6-6/97. Edited by L. Meites. New York: McGraw-Hill.

Cox, C. D. (1982). Effect of pyochelin on the virulence of Pseudomonas aeruginosa. Infection and Immunity 36, 17-23.

Cox, C. D. (1989). Importance of iron in bacterial virulence. In Metal Ions and Bacteria, pp. 207-246. Edited by T. J. Beveridge \& R. J. Doyle. New York: John Wiley and Sons.

Cox, C. D. \& Graham, R. (1979). Isolation of an iron binding compound from Pseudomonas aeruginosa. Journal of Bacteriology 137, 357-364.

Cox, C. D., Rinelart, K. L., Moore, M. L. \& Cook, J. C. (1981). Pyochelin: novel structure of an iron-chelating growth promoter for Pseudomonas aeruginosa. Proceedings of the National Academy of Sciences of the United States of America 78, 4256-4260.

FeIGL, F. (1960). Salicylic acid (and salicilic esters). In Spot Tests in Organic Analysis, pp. 394-396. Edited by F. Feigl. Amsterdam: Elsevier.

Gensaerg, K., Hughes, K. \& Smith, A. (1992). Siderophore-specific induction of iron uptake in Pseudomonas aeruginosa. Journal of General Microbiology 138, 2381-2387.

Gullan, A. H., LewTs, A. G. \& Andersen, R. J. (1981). Quantitative determination of hydroxamic acids. Analytical Chemistry 53, 841-844.

Guterman, S. K. (1973). Colicin B: mode of action and inhibition by enterochelin. Journal of Bacteriology 114, 1217-1224.

Heinrichs, D. E., Young, L. \& Poole, K. (1991). Pyochelin-mediated iron transport in Pseudomonas aeruginosa: involvement of a high molecular-mass outer membrane protein. Infection and Immunity $\mathbf{5 9}$, $3680-3684$.

Keel, C., Volsard, C., Berling, C. H., Kahr, G. \& Défago, G. (1989). Iron sufficience, a prerequisite for suppression of tobacco black root rot by Pseudomonas fuorescens strain $\mathrm{CHAO}$ under gnotobiotic conditions. Phytopathology 79, 584-589.

KiRChNeR, J. G. (1967). Thin Layer Chromatography, p. 172. New York: John Wiley \& Sons.

Marshall, B. J. \& Ratledge, C. (1972). Salicylic acid biosynthesis and its control in Mycobacterium smegmatis. Biochimica et Biophysica Acta 264, 106-116.

MarTell, A. E. \& SMITH, R. M. (1977). Other organise ligands. In Critical Stability Constants, vol. 3, pp. 181-201. Edited by A. E. Martell \& R. M. Smith. New York and London: Plenum Press.

MEYER, J. M. (1992). Exogenous siderophore-mediated iron uptake in
Pseudomonas aeruginosa: possible involvement of porin $\mathrm{OprF}$ in iron translocation. Journal of General Microbiology 138, 951-958.

Meyer, J. M., Hohnadel, D. \& Hallé, F. (1989). Cepabactin from Pseudomonas cepacia, a new type of siderophore. Journal of General Microbiology 135, 1479-1487.

Meyer, J. M., Azelvandre, P. \& Georges, C. (1992). Iron metabolism in Pseudomonas: salicylic acid, a siderophore of Pseudomonas fluorescens CHAO. Biofactors 4, 23-27.

NeILANDS, J. B. (1981). Microbial iron compounds. Annual Review of Biochemistry 50, 715-731.

NeILANDS, J. B. (1982). Microbial envelope proteins related to iron. Annual Review of Microbiology 36, 285-309.

Palleroni, N. J. (1984). Pseudomonadaceae. In Bergey's Manual of Systematic Bacteriology, vol. 1, pp. 141-149. Edited by N. R. Krieg \& J. G. Holt. Baltimore: Williams and Wilkins.

RATLEDGE, C. (1987). Iron metabolism in mycobacteria. In Iron Transport in Microbes, Plants and Animals, pp. 207-221. Edited by G. Winkelmann, D. van der Helm \& J. B. Neilands, Weinheim: $\mathrm{VCH}$.

RATLEDGE, C. \& WINDER, F. G. (1962). The accumulation of salicylic acid in mycobacteria during growth on an iron-deficient medium. Biochemistry 84, 501-506.

Ratledge, C., Macham, L. P., Brown, K. A. \& Marhall, B. J. (1974). Iron transport in Mycobacterium smegmatis: a restricted role for salicylic acid in the extracellular environment. Biochimica et Biophysica Acta 372, 39-51.

Saxena, B., Mayuranki, M. \& Modi, V. V. (1986). Isolation and characterization of siderophores from Azospirillum lipoferum D-2. Journal of General Microbiology 132, 2219-2224.

SoKoL, P. A. (1986). Production and utilization of pyochelin by clinical isolates of Pseudomonas cepacia. Journal of Clinical Microbiology 23, $560-562$.

SokoL, P. A. \& Woons, D. E. (1983). Demonstration of an iron siderophore-binding protein in the outer membrane of Pseudomonas aeruginosa. Infection and Immunity 40, 665-669.

Sokol, P. A. \& Woons, D. E. (1988). Effect of pyochelin on Pseudomonas cepacia respiratory infections. Microbial Pathogenesis 5, 197-205.

Sokol, P. A., Lewis, C. J. \& DenNis, J. J. (1992). Isolation of a novel siderophore from Pseudomonas cepacia. Journal of Medical Microbiology 36, 184-189.

StuTZ, E. W., DÉFAGo, G. \& KerN, H. (1986). Naturally occurring fluorescent pseudomonads involved in suppression of black root rot of tobacco. Phytopathology 76, 181-185.

UNGaR, G., DamGaARD, E. \& WONG, W. K. (1952). Determination of salicylic acid and related substances by ultraviolet spectrophotometry. Proceedings of the Society for Experimental Biology and Medicine 80, 45-47.

Visca, P., Chiarint, F., Vetriani, C., Mansi, A., Serino, L. \& Orsi, N. (1991). Epidemiological typing of uropathogenic Pseudomonas aeruginosa strains from hospitalised patients. Journal of Hospital Infection 19, 153-165.

Visca, P., Chiarini, F., Mansi, A., Vetriani, C., Serino, L. \& Orsi, N. (1992a). Virulence determinants in Pseudomonas aeruginosa strains from urinary tract infections. Epidemiology and Infection 108 , 323-336.

Visca, P., Colotti, G., Serino, L., Verzili, D., Orsi, N. \& Chiancone, E. $(1992 b)$. Metal regulation of siderophore synthesis in Pseudomonas aeruginosa and functional effects of siderophore-metal complexes. Applied and Environmental Microbiology 58, 2886-2893.

WeINBERG, E. D. (1978). Iron and infection. Microbiological Reviews 42, 45-66.

Weisster, A. \& White, C. E. (1963). Fluorescence analysis. In Handbook of Analytical Chemistry, pp. 6/176-6/196. Edited by L. Meites. New York: McGraw-Hill. 